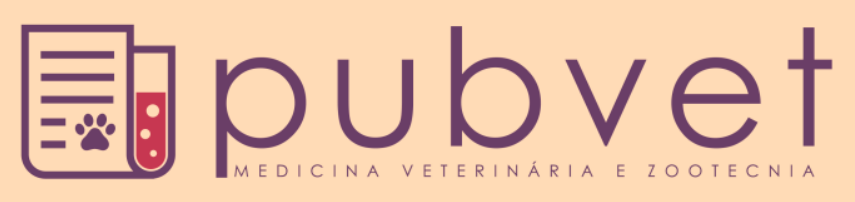

https://doi.org/10.22256/pubvet.v12n7a127.1-5

\title{
Fibrossarcoma oral de baixo grau histológico e elevada agressividade biológica: relato de caso
}

\author{
Marcel Vasconcellos ${ }^{1 * 0}$ \\ ${ }^{1}$ Doutorando do Programa de Pós-Graduação em Ciências Cirúrgicas da Faculdade de Medicina da \\ UFRJ.*Autor para correspondência.E-mail: marcelvasconcellos@yahoo.com.br
}

\begin{abstract}
RESUMO. O objetivo deste relato foi descrever a ocorrência de um fibrossarcoma em uma cadela da raça Golden Retriever, com 12 anos de idade, pesando $42 \mathrm{~kg}$. O animal apresentou histórico clínico de aumento do volume do plano nasal. Ao exame específico da cavidade oral, foi encontrada uma massa aderida à porção rostral do maxilar, encapsulada, medindo cerca de $5 \mathrm{~cm}$ de diâmetro, que se estendia cranialmente ao plano nasal, causando sua obstrução. Foi realizada biópsia incisional e o diagnóstico realizado com base na avaliação histopatológica. $\mathrm{O}$ animal foi submetido à quimioterapia neoadjuvante citorredutora e maxilectomia rostral bilateral. Até o momento não foi observada recidiva locorregional ou doença metastática. No Brasil, ainda são escassos os relatos de literatura envolvendo cirurgias radicais ou reconstrutivas em tumores oronasais.
\end{abstract}

Palavras chave: cães, tumor, neoplasias da cavidade oral

\section{Oral fibrosarcoma of low histological grade and high biological aggressiveness: case report}

ABSTRACT. The objective of this report was to describe the occurrence of a fibrosarcoma in a 12-year-old golden retriever, weighing $42 \mathrm{~kg}$. The animal presented a clinical history of increased nasal plane volume. At the specific examination of the oral cavity, a mass adhered to the rostral portion of the maxilla was found, encapsulated, measuring about 5 $\mathrm{cm}$ in diameter, which extended cranially to the nasal plane, causing its obstruction. An incisional biopsy was performed and the diagnosis was made based on the histopathological evaluation. The animal was submitted to neoadjuvant chemoradiotherapy and bilateral rostral maxilectomy. To date no locoregional recurrence or metastatic disease has been observed. In Brazil, reports of literature involving radical or reconstructive surgeries in oronasal tumors are still scarce.

Keywords: dogs, tumor, oral cavity neoplasias

\section{Fibrosarcoma oral de bajo grado histológico y elevada agresividad biológica: reporte de un caso}

RESUMEN. El objetivo de este relato fue describir el caso de un fibrosarcoma en una perra de raza Golden Retriever, con 12 años de edad, pesando $42 \mathrm{~kg}$. El animal presentó un historial clínico de aumento del volumen del plano nasal. En el examen específico de la cavidad oral, se encontró una masa adherida a la porción rostral del maxilar, encapsulada, midiendo cerca de $5 \mathrm{~cm}$ de diámetro, que se extendía cranealmente al plano nasal, causando su obstrucción. Se realizó biopsia incisional y el diagnóstico realizado con base en la evaluación histopatológica. El animal fue sometido a quimioterapia citorreductora y 
maxilectomía rostral bilateral. Hasta el momento no se ha observado recidiva locorregional o enfermedad metastática. En Brasil, todavía son escasos los relatos de literatura envolviendo cirugías radicales o reconstructivas en tumores oronasales.

Palabras clave: perros, tumor, neoplasias de la cavidad oral

\section{Introdução}

O fibrossarcoma oral é uma neoplasia maligna de origem mesenquimal constituída por fibrócitos e fibroblastos. Apresenta maior incidência em cães machos adultos entre 7 e 12 anos, representando cerca de 7,5 a $25 \%$ de todos os casos de câncer da cavidade oral (Liptak \& Withrow, 2007).

Historicamente a ressecção cirúrgica radical tem desempenhado um importante papel em seu controle, sendo muito bem tolerada nos cães (Lascelles et al., 2004, Liptak \& Withrow, 2007).

Embora a taxa de recidiva locorregional seja elevada (32\%-57\%), e a maior causa de óbito nesses pacientes (Frazier et al., 2012), um estudo de referência com tumores mesenquimais, observou que cães com margens cirúrgicas histologicamente incompletas foram 10,5 vezes mais propensos a desenvolver recidiva local do que cães com margens completas (Kuntz et al., 1997).

Buscando estabelecer padrões de margens de segurança em tumores orais, Salisbury (2003) e Liptak \& Withrow (2012), propugnaram margens de 1 e $2 \mathrm{~cm}$, contrapondo-se ao trabalho anterior de Dernell et al. (1998), os quais preconizaram margens mais extensas, de até $3 \mathrm{~cm}$ na exérese neoplásica.

Em meio a ausência de padrões definitivos e limitações anatômicas inerentes à cirurgia oral, Lascelles et al. (2004) descreveram o uso da maxilectomia radical rostral bilateral, com intenção de obter margens histologicamente livres e subsequente aumento do tempo de sobrevida livre de progressão.

Há de se considerar, no entanto, que relatos de recorrência tumoral em tumores mesenquimais, apesar de uma ressecção histologicamente completa, bem como de tumores que não recidivaram mediante excisão incompleta, são encontrados na literatura e na prática clínica (Milovancev \& Russel, 2017).

Conceitualmente as causas de recidiva locorregional nos tumores orais, foram revistas por Wolf (2012), que propugnou que a adequação da margem cirúrgica se relaciona muito mais com a resposta imune do hospedeiro e com a biologia molecular das células tumorais na frente invasora, do que com qualquer fator anatômico. Ademais, Milovancev \& Russel (2017), corroborando com a proposição, aduziram que a recorrência, pode estar intrinsecamente relacionada aos conceitos de campo de cancerização, heterogeneidade intratumoral e microambiente tumoral.

Em que pese uma análise crítica dos resultados e conceitos ora apresentados, o trabalho descreve o uso de um procedimento cirúrgico com bons resultados estéticos, funcionais e oncológicos. Sua relevância justifica-se pelo número significativo de animais diagnosticados com tumores oronasais que ainda são eutanasiados, sem que de fato, seja oferecida, ainda que paliativa, uma opção terapêutica.

\section{Relato de caso}

Foi atendida na Clínica Veterinária "Clinicão", localizada no município de Resende-RJ, uma cadela de 12 anos da raça Golden Retriever, $42 \mathrm{~kg}$, com histórico de súbito aumento de volume no plano nasal (Figura 1a). Na anamnese foi relatado um aumento do plano nasal, associado a um provável traumatismo. $\mathrm{O}$ exame físico, demonstrou a presença de uma massa aderida à porção rostral do maxilar, encapsulada, medindo cerca de $5 \mathrm{~cm}$ de diâmetro, que se estendia cranialmente ao plano nasal, causando sua obstrução. Os demais parâmetros clínicos não apresentavam alterações. Após sedação com acepromazina a $0,2 \%$, via IM, realizou-se a inspeção de toda a cavidade oral e pescoço, não se constatando na palpação aumento de linfonodos superficiais.

Coletou-se sangue para realização de exames de rotina tais como: hemograma completo, bioquímica sérica hepática e renal, verificando-se estarem dentro dos padrões de referência. Procedeu-se ao exame radiográfico do crânio e do tórax (Figura 1b,1c), não se constatando invasão óssea ou metástases pulmonares. Após as avaliações clínicas preliminares, procedeu-se a biópsia incisional. Foram colhidas 3 amostras tumorais, fixadas em formaldeído tamponado a $10 \%$, e encaminhadas a exame histopatológico. 


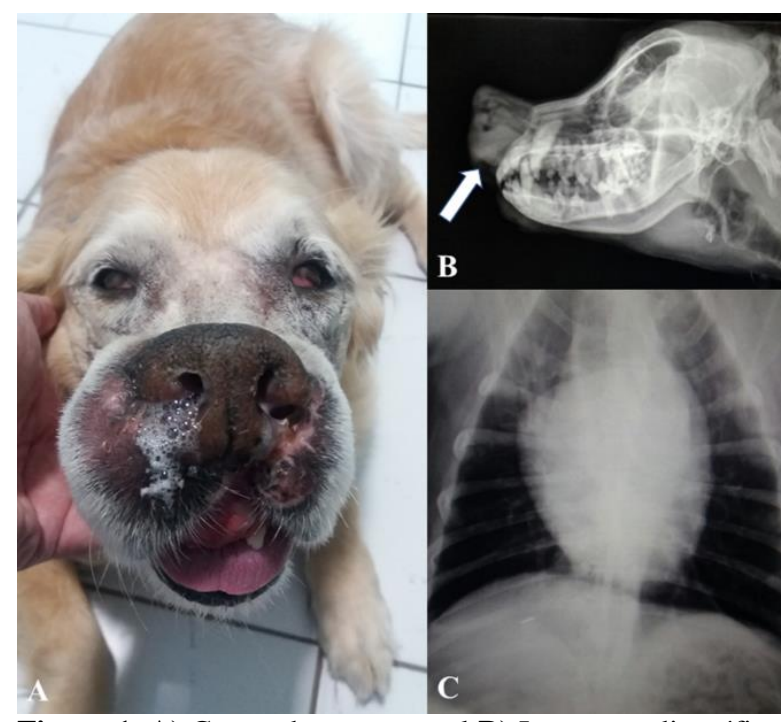

Figura 1. A) Grave obstrução nasal B) Imagem radiográfica em projeção lateral evidenciando tumor em região rostral do maxilar, causando aumento e elevação do plano nasal (seta) C) Projeção dorso-ventral torácica, sugestiva de ausência de metastáses pulmonares.

A avaliação histopatológica, revelou tratar-se de uma neoplasia mesenquimal fusocelular, disposta em feixes, com infiltração no tecido muscular. A neoplasia apresentou leves atipias e raríssimas mitoses. O diagnóstico definitivo foi de fibrossarcoma de baixo grau histológico.

De acordo com a classificação TNM para tumores sólidos em animais domésticos (Owen, 1980), o tumor foi estadiado (T3a: N0; M0), e classificado como de terceiro estadio (estadio avançado).

O proprietário do paciente foi orientado, quanto as opções terapêuticas disponíveis, a elevada taxa de recidiva locorregional, possibilidade de desenvolvimento metastático e prognóstico reservado.

Optou-se inicialmente pela quimioterapia neoadjuvante (citorredutora) buscando diminuir a extensão da ressecção cirúrgica e restringir a disseminação neoplásica. Foi utilizado cloridrato de doxorrubicina, $30 \mathrm{mg} / \mathrm{m}^{2}$, via IV, a cada 21 dias, além do uso contínuo de um inibidor da cicloxigenase- 2 , piroxicam $(0,3 \mathrm{mg} / \mathrm{kg} / \mathrm{SID} / \mathrm{VO})$. $\mathrm{Na}$ segunda sessão, devido ao agravamento do quadro respiratório e ausência de resposta terapêutica, procedeu-se a intervenção cirúrgica. Por se tratar de procedimento mutilador, mostrouse previamente ao proprietário o aspecto estético de outros animais submetidos a esta intervenção.

Após jejum hídrico por 4 horas e alimentar por 12 horas, o animal foi conduzido ao centro cirúrgico. Após cuidados de assepsia e antissepsia, o procedimento pré-anestésico foi realizado, utilizando como medicação pré-anestésica 0,05 $\mathrm{mg} / \mathrm{kg} / \mathrm{IM}$ de acepromazina a $0,2 \%$, seguindo-se indução com propofol $1 \%(5 \mathrm{mg} / \mathrm{kg} / \mathrm{IV})$. Efetuouse a intubação orotraqueal com auxílio de laringoscópio, sendo o animal mantido em plano cirúrgico por meio de circuito anestésico semifechado com uso de isoflurano. Após a divulsão do tecido peritumoral (Figura 2a), procedeu-se a osteotomia do osso maxilar entre o dente canino e o primeiro pré-molar (PM1), com uso de serra oscilatória e irrigação local com salina fisiológica para evitar necrose térmica. Na síntese da mucosa oral e pele utilizou-se respectivamente, fio absorvível de poliglactina 910 3.0, e náilon 2.0, ambos em pontos simples interrompidos. O plano nasal foi ressecado e a hemorragia controlada por eletrocoagulação, procedendo-se a seguir sua reconstrução (Figura 2b, 2c).

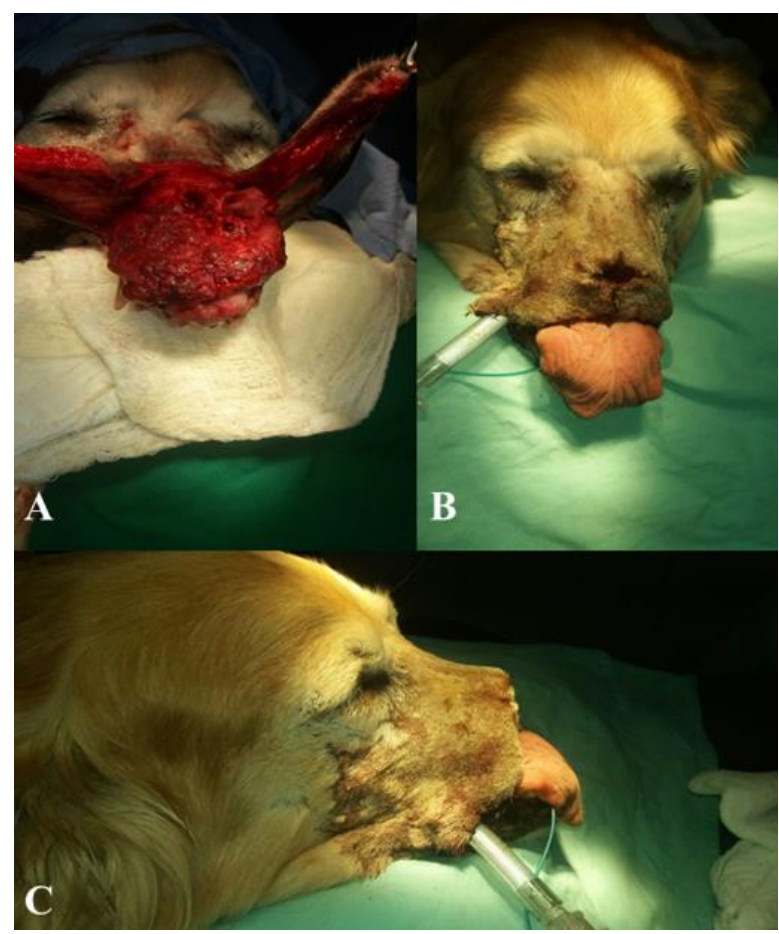

Figura 2. A) Extensa invasão neoplásica do plano nasal B) Acesso cirúrgico ao maxilar C) Aspecto lateral após planectomia nasal.

\section{Resultados}

Após o procedimento cirúrgico, prescreveu-se $2 \mathrm{mg} / \mathrm{kg} / \mathrm{TID} / \mathrm{VO}$ de cloridrato de tramadol durante dez dias, $0,2 \mathrm{mg} / \mathrm{kg} / \mathrm{SID} / \mathrm{VO}$ de meloxicam por cinco dias, além de 22 $\mathrm{mg} / \mathrm{kg} / \mathrm{SID} / \mathrm{VO}$ da associação de metronidazol e espiramicina durante sete dias. Um colar elizabetano foi colocado para evitar automutilação. A sonda esofágica foi usada por cinco dias em que uma dieta pastosa $\left(\mathrm{a} / \mathrm{d}^{\mathrm{TM}}\right.$ 
Canine/Feline Critical Care, da Hills Pet Nutrition ${ }^{\circledR}$ ) e os medicamentos foram administrados. A cavidade oral foi higienizada com digluconato de clorexidina $0,12 \%$ sem álcool, por 10 dias. $\mathrm{O}$ animal recebeu alta após sete dias.

Após 30 dias, animal retornou à clínica, sendo realizados exames clínicos e radiográficos do crânio e tórax. Não foram observados sinais de recidiva tumoral ou disseminação metastática pulmonar. Constatou-se um bom resultado estético pós-cirúgico aos sete e 30 dias, como demonstrados na figura $3 \mathrm{~A}$ e $3 \mathrm{~B}$.

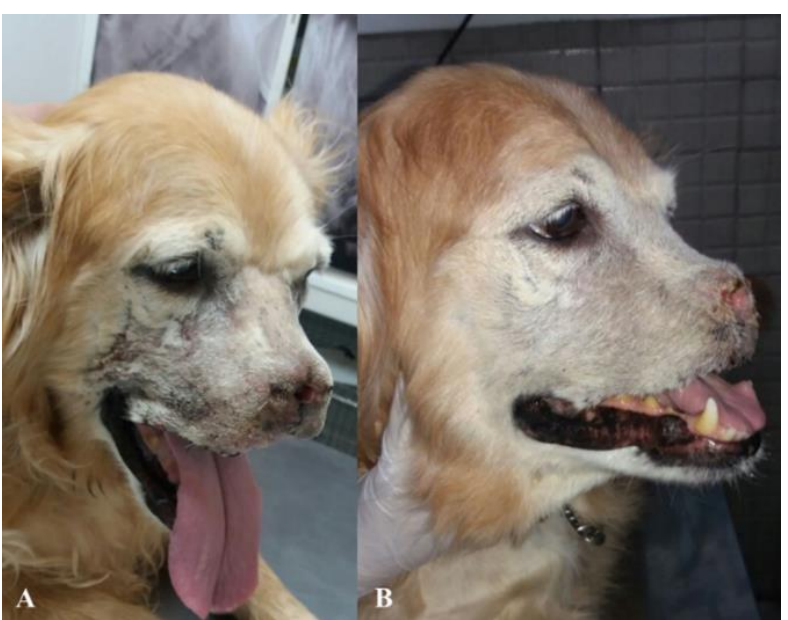

Figura 3. A) Aspecto do animal aos sete dias B) Resultado estético aos 30 dias.

\section{Discussão}

A rápida e agressiva evolução clínica observada neste caso, foi estudada por Ciekot et al. (1994) os quais relataram que em cães de raças grandes, especialmente no Golden Retriever, a associação de um baixo grau histológico e uma elevada agressividade biológica ocorrem em 54\% dos animais, e em $72 \%$ dos casos, na maxila.

Liptak \& Withrow (2012), descreveram que os tumores orais são fortemente influenciados pelo grau de inflamação e necrose, dificultando sua interpretação citológica. Diante do acentuado processo inflamatório, optou-se pela avaliação histopatológica considerada padrão-ouro no diagnóstico das neoplasias orais.

A avaliação da extensão tumoral, foi de certo modo, prejudicada, por restringir-se apenas ao exame radiográfico do crânio. Um estudo comparativo de Ghirelli et al. (2013), em 21 cães, sobre a eficácia da técnica radiográfica convencional versus tomografia computadorizada (TC), na avaliação da invasão de estruturas adjacentes aos tumores de localização oral, os autores observaram uma eficiência de $95.2 \%$ da TC contra $30 \%$ do exame radiológico convencional.

Embora os maiores tempos de sobrevivência e controle locorregional, tenham sido obtidos com o uso combinado das modalidades cirúrgica e radioterápica (Frazier et al., 2012, Gardner et al., 2015), a dificuldade de acesso e custos ainda elevados com tratamento radioterápico, nos direcionou a um tratamento quimioterápico neoadjuvante e cirúrgico.

Quanto ao uso de agentes antineoplásicos, a literatura cita alguma resposta (Liptak \& Withrow, 2007), e desse modo, foi utilizado tratamento citorredutor com uso de cloridrato de doxorrubicina, além de um inibidor da cicloxigenase-2. Não foi observada nenhuma resposta, e em razão do agravamento do quadro respiratório, procedeu-se à cirurgia.

Durante o procedimento cirúrgico, não se efetuou o mapeamento e a biópsia dos linfonodos sentinela, considerando que devido ao padrão imprevisível da drenagem linfática cervical (Liptak \& Withrow, 2012), isto exigiria uma abordagem cirúrgica mais extensa, e presumivelmente, aumentaria o risco de complicações pós-operatórias.

Em relação ao procedimento, o resultado funcional foi considerado muito bom, pois logo após a retirada da sonda gástrica, o animal alimentou-se normalmente. Observou-se que durante a apreensão do alimento, devido à ausência dos dentes incisivos superiores, esta ocorreu de modo tempestuoso, exigindo um comedouro de maior profundidade e largura, para evitar o desperdício de alimento. $\mathrm{O}$ animal apresentou uma leve descarga nasal, o que, segundo Lascelles et al. (2004), é persistente após a maxilectomia.

Esteticamente, o resultado foi aceitável pelo proprietário, corroborando com as observações de Liptak \& Withrow (2012), que citaram uma taxa de aceitação de $80 \%$ após a cirurgia.

Embora o tempo de sobrevida livre da doença atual e follow-up seja apenas de 30 dias, e que ainda seja elevada a probabilidade de uma recidiva locorregional (Frazier et al., 2012), tumores rostrais da cavidade oral estão associados a um melhor prognóstico.

\section{Conclusão}

No Brasil, ainda são escassos os relatos de literatura envolvendo cirurgias radicais ou reconstrutivas em tumores da cavidade oral. Em que pese que um número significativo de animais 
nestas condições são eutanasiados, os relatos de bons resultados estéticos, funcionais $\mathrm{e}$ oncológicos, representam um incentivo a estudos prospectivos em tumores de ocorrência espontânea.

\section{Agradecimentos}

À equipe da Clínica Veterinária "CLINICÃO" de Resende-RJ, em especial à Dra. Juliana Carreiro de Ávila Furtado Boareto, e ao Enfermeiro Veterinário Antonio Araújo da Silva Carvalho, pela dedicação e profissionalismo.

\section{Referências bibliográficas}

Ciekot, P.A., Powers, B. E., Withrow, S. J., Straw, R. C., Ogilvie, G. K. \& LaReu, S. M. 1994. Histologically low-grade, yet biologically high-grade, fibrosarcomas of the mandible and maxilla in dogs: 25 cases (1982-1991). Journal of the American Veterinary Medical Association, 204(4), 610-615.

Dernell, W. S., Withrow, S. J., Kuntz, C. A. \& Powers B. E. 1998. Principles of treatment for soft tissue sarcoma. Clinical Techniques in Small Animal Practice, 13, 59-64.

Frazier, S. A., Johns, S. M., Ortega, J., Zwingenberger, A. L., Kent, M. S., Hammond G. M., ... Skorupski, K. A. 2012. Outcome in dogs with surgically resected oral fibrosarcoma (1997-2008). Veterinary and Comparative. Oncological, 10(1), 33-43.

Gardner, H., Fidel, J., Haldorson, G., Dernell, W. \& Wheeler, B. 2015. Canine oral fibrosarcomas: A retrospective analysis of 65 cases (1998-2010). Veterinary and Comparative. Oncological, 13(1), 40-47.

Ghirelli, C. O., Villamizar, L. A. \& Pinto, A. C. 2013. Comparison of standard radiography and computed tomography in 21 dogs with maxillary masses. Journal of Veterinary Dentistry, 30, 72-76.

Kuntz, C. A., Dernell, W. S., Powers, B. E., Devitt, C., Straw, R. C. \& Withrow, S. J. 1997.
Prognostic factors for surgical treatment of soft-tissue sarcomas in dogs: 75 cases (19861996). Journal of the American Veterinary Medical Association, 211(9), 1147-1151.

Lascellles, B. D., Henderson R. A., Seguin B., Liptak J. M. \& Withrow, S. J. 2004. Bilateral rostral maxillectomy and nasal planectomy for large rostral maxillofacial neoplasms in six dogs and one cat. Journal of the American Animal Hospital Association, 40(2), 137-146.

Liptak, J. M. \& Withrow, S. J. 2007. Oral tumours. . In: Withrow, S. J. \& Vail, D. M. (eds) Small animal clinical oncology (p. 455-475). Saunders Elsevier, St Louis, Missouri, Estados Unidos.

Liptak, J. M. \& Withrow, S. J. 2012. Cancer of the Gastrointestinal Tract. In: Withrow, S. J. \& Vail, D. M. (eds.). Withrow and MacEwen's Small Animal Clinical Oncology (5a ed, p.381431). Saunders Elsevier, St Louis, Missouri, Estados Unidos.

Milovancev, M. \& Russel, D. S. 2017. Surgical margins in the veterinary cancer patient. Veterinary and Comparative. Oncological, 15(4),1136-1157.

Salisbury, S. K. 2003. Maxillectomy and mandibulectomy. In: Slatter, D. H. (ed) Textbook of Small Animal Surgery (3a ed., p. 561-572). Saunders, Philadelphia, Pensilvânia, Estados Unidos.

Wolf, G. T. 2012. Surgical margins in the genomic era: the hayes martin lecture. Arch Otolaryngol Head Neck Surgery, 138, 1001-1013.

Recebido: 31 mar. 2018.

Aprovado: 21 abr. 2018

Publicado: 5 jul. 2018

Licenciamento: Este artigo é publicado na modalidade Acesso Aberto sob a licença Creative Commons Atribuição 4.0 (CC-BY 4.0), a qual permite uso irrestrito, distribuição, reprodução em qualquer meio, desde que o autor e a fonte sejam devidamente creditados. 